\title{
Origin of Estrogen in Women Pregnant with an Anencephalic Fetus*
}

\author{
Paul C. MacDonald † and Pentti K. Siiteri \\ (From the Department of Obstetrics-Gynecology, the University of Texas, Southwestern \\ Medical School, and Parkland Memorial Hospital, Dallas, Texas)
}

While maternal estrogen excretion increases markedly during the course of pregnancy with a normal fetus, Frandsen and Stakeman found that women pregnant with an anencephalic fetus excrete relatively smaller amounts of urinary estrogens (1). Pointing to the characteristic absence of the fetal zone of the adrenal cortex in anencephaly, these authors postulated that the normal fetal adrenal produces a substance that serves as a precursor for estrogen biosynthesis by the placenta (2). Several other lines of evidence suggest that estrogen production in the placenta arises from the utilization of externally supplied steroidal precursors rather than by de novo synthetic mechanisms. Levitz, Emerman, and Dancis were unable to demonstrate estrogen formation in placental systems in vitro from simple precursors such as acetate (3). On the other hand, the conversion of preformed neutral steroids such as testosterone, ${ }^{1}$ androstenedione, and dehydroisoandrosterone to estrone and/or estradiol by placental preparations in vitro is remarkably efficient as first demonstrated by Ryan (4).

\footnotetext{
* Submitted for publication August 10, 1964 ; accepted December 1, 1964.

A preliminary report of a portion of this study was presented to the Workshop on Estrogens, Orcas Island, Wash., June 1963.

This study was supported, in part, by grants AM 0691202 and HD 00107-01, U. S. Public Health Service.

$\dagger$ Address requests for reprints to: Dr. Paul C. MacDonald, The University of Texas, Southwestern Medical School, Dallas, Texas 75235.

1 Trivial names are used in the text for the following compounds: testosterone, 17 $\beta$-hydroxy-androst-4-en-3one; androstenedione, androst-4-en-3,17-dione; dehydroisoandrosterone, $3 \beta$-hydroxy-androst-5-en-17-one; dehydroisoandrosterone sulfate, 17 -oxo-androst-5-en-3 $\beta$-ylsulfate; $16 \alpha$-hydroxydehydroisoandrosterone, $3 \beta, 16 \alpha$-dihydroxy-androst-5-en-17-one ; estrone, 3-hydroxy-estra-1, 3,5(10)-trien-17-one; estradiol, estra-1,3,5(10)-trien-3, 17 $\beta$-diol; estriol, estra-1,3,5(10)-trien-3,16 $\alpha, 17 \beta$-triol.
}

Indeed, more recent in vivo studies have shown that several $\mathrm{C}_{19}$ steroids are converted to estrogen when introduced into the circulation of pregnant women. Previous studies in these laboratories have demonstrated that dehydroisoandrosterone (D), present in the maternal circulation as a sulfate ester [dehydroisoandrosterone sulfate (DS) ], serves as a quantitatively important precursor of estrogen during normal and abnormal pregnancy (5-7). In addition to D and DS, the conversion of testosterone and androstenedione to urinary estrogens by pregnant women has been demonstrated by Baulieu and Dray (8). Similarly, Bolté and associates $(9,10)$ as well as Warren and Timberlake (11) found radioactive urinary estrogens after the administration of isotope-labeled DS to pregnant women. In addition Bolté and co-workers have also demonstrated aromatization of radioactive $\mathrm{D}, \mathrm{DS}$, androstenedione, and testosterone when these were perfused through the in situ placenta via the fetal vessels after disconnecting the fetus in early pregnancy (12).

All of these studies support the concept of placental estrogen production from externally supplied precursors. Of the circulating steroids known to be available for this process, DS, which has recently been shown to be a normal adrenal secretory product (13), appears to be most important in view of its presence in high concentration in both maternal and fetal blood $(14,15)$. However, the relative quantitative importance of these two sources (maternal and fetal) of precursor DS for placental estrogen formation remains to be evaluated.

Women pregnant with an anencephalic fetus represent an interesting biological circumstance for study of this problem since the amount of DS arising in the fetal compartment is minimal as evidenced by the absence of DS in the cord blood 
of anencephalic monsters studied by Nichols, Lescure, and Migeon (16). The purpose of the present experiments was to determine the source and mechanism of origin of estrogen in four women pregnant with an anencephalic fetus. The results of this study indicate that the bulk (50 to $100 \%$ ) of the estrogen entering the maternal compartment in these subjects was derived from dehydroisoandrosterone sulfate circulating in the maternal plasma. In addition, it is shown that the administration of dexamethasone $(11 \beta, 17 \alpha, 21$ trihydroxy-9 $\alpha$-fluoro-16 $\alpha$-methyl-pregn-1,4-dien-3, 20 -dione) to one of these subjects resulted in a decrease in the dehydroisoandrosterone sulfate production rate and a concomitant decrease in the estradiol production rate. ${ }^{2}$ Conversely, the administration of ACTH to another of these subjects resulted in an increase in the daily production rate of dehydroisoandrosterone sulfate and a proportionate increase in the production rate of estradiol.

\section{Methods}

Expcrimental design. In each study the radioactive hormone tracers were dissolved in $10 \mathrm{ml}$ of $10 \%$ ethanol in water and administered intravenously. Thereafter, in each case, the subject's urine was collected for 5 days into an iced container. At the end of the collection period the urine samples were processed as described below. Preliminary studies indicated that more than $95 \%$ of the radioactive urinary metabolites under study are excreted within 5 days.

Experiments I and II were performed in subject M.M., a 34-year-old Negro, 38 weeks pregnant with a live anencephalic fetus (MM-38). The first study (experiment I) involved the administration of a tracer dose of 6,7- $\mathrm{H}^{8}$-estradiol $\left(\mathrm{E} 2 \mathrm{H}^{3}\right)$ and $4-\mathrm{C}^{14}$-progesterone followed by urine collection as described above. Five days after the comp'etion of experiment I, a tracer dose of $\mathrm{E}^{2} \mathrm{H}^{3}$ and $4-C^{14}$-dehydroisoandrosterone suifate $\left(D^{14} S\right)$ was administered, and urine was again collected as before (experiment II).

Experiment III was performed in subject A.B., a 37-year-old Caucasian, 35 weeks pregnant with a live anencephalic fetus (AB-35). For this study, a tracer

2 By the techniques used in this study the placental conversion of dehydroisoandrosterone sulfate to estradiol cannot be distinguished from its conversion to estrone. For convenience, the conversion of DS to estrone and/or estradiol and the production rate of estrone-estradiol are referred to in the text as simply the conversion to or production of estradiol. In all cases almost identical results were obtained if the values for either urinary estrone or estradiol were used for the calculations. dose of $\mathrm{E}_{2} \mathrm{H}^{3}$ and $\mathrm{D}^{\mathrm{C}^{14}} \mathrm{~S}$ was administered before urine collection.

Experiments IVa and IVb were performed in subject L.B., a 21-year-old Negro, 33 weeks pregnant with a live anencephalic fetus (LB-33). First, a tracer dose of $\mathrm{E} 2 \mathrm{H}^{3}$ and $\mathrm{D}^{\mathrm{C}^{14}} \mathrm{~S}$ was administered (experiment IVa). After the fifth day of urine collection, this patient received dexamethasone, $0.75 \mathrm{mg}$ by mouth every 6 hours for 17 days. On day 11 of treatment with dexamethasone, a second tracer dose of $\mathrm{E}_{2} \mathrm{H}^{3}$ and $\mathrm{D}^{\mathrm{C}}{ }^{14} \mathrm{~S}$ was administered (experiment IVb).

Experiments $\mathrm{Va}$ and $\mathrm{Vb}$ were performed in subject J.V., a 24-year-old Caucasian, 35 weeks pregnant with a live anencephalic fetus (JV-35). Experiment $\mathrm{Va}$ involved the administration of a tracer dose of $\mathrm{E} 2 \mathrm{H}^{3}$ and $\mathrm{D}^{\mathrm{C}^{14} \mathrm{~S}}$ after which the usual 5-day urine collection was achieved. After the completion of experiment $\mathrm{Va}, 30 \mathrm{U}$ of ACTH was administered intramuscularly to this subject every 12 hours for 9 days. On day 4 of treatment with $\mathrm{ACTH}$, a second tracer dose of $\mathrm{E} 2 \mathrm{H}^{3}$ and $\mathrm{D}^{\mathrm{C}}{ }^{14} \mathrm{~S}$ was given intravenously, and urine was collected as before (experiment $\mathrm{Vb}$ ).

In each experiment urinary estrone (E1), estradiol (E2), and estriol (E3) were isolated, and their specific activities relative to tritium and to $\mathrm{C}^{14}$ were determined. Similarly, in all studies except experiment I, urinary dehydroisoandrosterone was isolated, and its specific activity relative to $\mathrm{C}^{\mathbf{1 4}}$ was determined.

The methods of tracer preparation, urine processing, and hydrolysis, as well as extraction and purification of the urinary metabolites, dehydroisoandrosterone (sulfate), estrone, estradiol, and estriol (glucuronosides), and determination of their specific activities have been described in detail (17).

In each experiment, $80 \%$ of the 5-day urine pool was adjusted to $\mathrm{pH} 5.0$ and incubated with $\beta$-glucuronidase ${ }^{3}$ for 72 hours at $37^{\circ} \mathrm{C}$. The liberated steroids were extracted with ethyl acetate. After removal of the solvent, neutral and phenolic steroids were separated by partition between diethyl ether and $2 \mathrm{~N} \mathrm{NaOH}$. Estrogens present in the phenolic fraction were purified by chromatographic procedures previously described. First a gradient elution partition chromatographic system employing Celite as support for the stationary phase, ethylene glycol, and utilizing 2,2,4-trimethylpentane (isooctane) containing progressively increasing quantities of ethyl acetate as mobile phase effected initial separation of the estrogen metabolites. The fractions containing estrone, estradiol, and estriol were separately combined and rechromatographed by liquid-liquid partition chromatography on Celite by systems containing isooctane, $t$-butanol, methanol, and water in various ratios as applicable to each estrogen metabolite. After further purification by thin-layer chromatography (TLC), specific activities of each of the urinary estrogen metabolites were determined by the double isotope derivative technique after acetylation of separate samples of each

\footnotetext{
${ }^{3}$ Ketodase, Warner-Chilcott Laboratories, Morris Plains, N. J.
} 
metabolite with isotope-labeled and nonradioactive acetic anhydride. The resulting estrogen acetates were chromatographed by TLC on silica gel $\mathrm{G}$ using chloroform as the developing solvent. After TLC, the estrogen acetates were eluted from the silica gel, the appropriate nonradioactive carrier estrogen acetate was added, and recrystallization was carried out until the $\mathrm{H}^{8} / \mathrm{C}^{14}$ ratios in successive crystals and mother liquors were identical. Specific activities were calculated from the final $\mathrm{H}^{3} / \mathrm{C}^{14}$ ratios of both types of acetates obtained from each of the metabolites E1, E2, and E3, as previously described (17).

The residual urine obtained after ethyl acetate extraction of the steroids liberated by $\beta$-glucuronidase was subjected to solvolysis using tetrahydrofuran in order to cleave steroid sulfates (18). The liberated neutral and phenolic steroids thus obtained were again separated by partition between ether and $\mathrm{NaOH}$ solution. The neutral fraction was chromatographed on Celite with a system of isooctane: $t$-butanol/methanol: water $(500: 100 /$ $350: 50$ ) (19). The fractions containing dehydroisoandrosterone were combined, and after solvent removal the residue was chromatographed on Whatman 1 filter paper with petroleum ether (bp 60 to $110^{\circ} \mathrm{C}$ ) $/ 90 \%$ methanol. The specific activity of the purified dehydroisoandrosterone was determined by assay of radioactivity and the micro-Zimmerman reaction (20). Phenolic steroids obtained from the sulfate fraction were not analyzed in each study since no significant differences between the specific activities of urinary estrogen derived from glucuronide and sulfate fractions were observed in the first case studied (MM-38, experiment II).

Calculations. The fraction of the administered $\mathrm{C}^{14}$ labeled DS converted to estradiol 4 is calculated from the relationship of the $\mathrm{H}^{3} / \mathrm{C}^{14}$ ratio of the isolated urinary E2 to that of the injected tracers, $D^{C^{14}} S$ and $\mathrm{E} 2 \mathrm{H}^{3}$. This calculation can be illustrated by the following hypothetical case in which $100 \%$ of the injected tracer $\mathrm{D}^{\mathrm{C}^{14} \mathrm{~S}}$ is converted to estradiol. Assume that the tracer dose injected consisted of $3 \times 10^{8} \mathrm{cpm}$ of $\mathrm{E} 2 \mathrm{H}^{3}$ and $5 \times 10^{6} \mathrm{cpm}$ of $\mathrm{D}^{\mathrm{C}^{14}} \mathrm{~S}, \mathrm{a} \mathrm{H}^{3} / \mathrm{C}^{14}$ ratio of 0.6 , and further assume that all of the injected $\mathrm{D}^{{ }^{14}} \mathrm{~S}$ tracer was converted to $\mathrm{E}^{\mathrm{C}^{14}}$. If both tracers of $\mathrm{E} 2$, that is the $\mathrm{E} 2 \mathrm{H}^{3}$ injected and the $\mathrm{E} 2^{\mathrm{C}^{14}}$ derived from injected $\mathrm{D}^{\mathrm{C} 14} \mathrm{~S}$, suffer a similar catabolic fate, the $\mathrm{H}^{3} / \mathrm{C}^{14}$ ratio of $\mathrm{E} 2$ metabolites in the urine will be identical with the $\mathrm{H}^{3} / \mathrm{C}^{14}$ ratio of the injected tracers, i.e., 0.6. However, if only $30 \%$ of the $\mathrm{D}^{\mathrm{C}}{ }^{14} \mathrm{~S}$ tracer was converted to E2 by the placenta, the resulting effective tracer dose of $\mathrm{E} 2$ would be: $\left(3 \times 10^{8} \mathrm{cpm} \mathrm{E} 2 \mathrm{H}^{3}\right) /\left(1.5 \times 10^{6} \mathrm{cpm}\right.$ $\mathrm{E}^{\mathrm{C}^{14}}$ ) (ratio $=2$ ), and the $\mathrm{H}^{3} / \mathrm{C}^{14}$ ratio of $\mathrm{E} 2$ metabolites in the urine would also be 2 . In the latter circumstance the fraction of $\mathrm{D}^{\mathrm{C}^{14}} \mathrm{~S}$ converted to $\mathrm{E} 2$ may

4 The calculated fraction of the administered $D^{C^{14}} \mathrm{~S}$ tracer converted to estradiol (and/or estrone) ${ }^{2}$ represents the extent of tissue (placental) conversion of $\mathrm{D}^{14} \mathrm{~S}$ to the hormone, estradiol (and/or estrone), and is not the fraction of the administered tracer appearing in urinary $\mathrm{E} 2$. be calculated from the expression:

$$
\begin{array}{ll}
\text { Per cent } \mathrm{D}^{\mathrm{C}^{14} \mathrm{~S} \longrightarrow} & \mathrm{E} 2=\frac{\mathrm{H}^{3} / \mathrm{C}^{14} \text { injected }}{\mathrm{H}^{3} / \mathrm{C}^{14} \mathrm{E} 2 \text { (urinary) }} \times 100, \\
\text { or } & \frac{0.6}{2.0} \times 100=30 \% .
\end{array}
$$

Implicit in this calculation is the assumption that the $\mathrm{C}^{14}$-labeled E2 derived from the injected $\mathrm{D}^{\mathrm{C}} \mathrm{S} \mathrm{S}$ tracer will behave identically with the injected tritium labeled E2 tracer; that qualitatively and quantitatively the two radioactive forms of $\mathrm{E} 2$ will suffer the same catabolic fate and ultimate urinary excretion. Rigid experimental validation of this assumption is not yet possible. Use of the above expression could yield erroneous values if a disproportionate amount of either of the two labeled forms of E2 was metabolized in the fetal compartment. Since the $\mathrm{C}^{\mathbf{1 4}}$-labeled $\mathrm{E} 2$ is formed from $\mathrm{DS}$ in the placenta (5), it seems likely that this tracer form of E2 might have greater access to the fetus than the tritiumlabeled E2 introduced into the antecubital vein of the mother. Metabolism of a significant amount of E2-C ${ }^{14}$ by the fetus without prior mixing in the maternal compartment would invalidate the above assumption. In this event, the amount of $\mathrm{E} 2-\mathrm{C}^{14}$ entering the maternal circulation would be diminished, and the amounts of carbon $^{14}$-labeled metabolites ultimately excreted in the maternal urine would not be representative of the total amount of $\mathrm{E} 2-\mathrm{C}^{14}$ formed in the placenta. Erroneously high urinary estrogen $\mathrm{H}^{3} / \mathrm{C}^{14}$ ratios would be observed, and the calculated extent of conversion of $\mathrm{D}^{\mathrm{C}^{14}} \mathrm{~S}$ to $\mathrm{E} 2$ would be underestimated.

From the experimental data presented below this problem is not detrimental to the point of this study, since in two experiments the specific activities of urinary E1, E2, and $\mathrm{E} 3$ with respect to $\mathrm{C}^{14}$ were maximal, as they were identical with that of urinary DS. These results indicate that in these subjects the total estrogen production of the placenta was derived from the utilization of DS circulating in the maternal compartment independent of what fraction of this total re-entered the maternal circulation. Preferential loss to the fetus of tracer E2 injected into the maternal circulation, which would result in an overestimate of the extent of conversion, is considered to be extremely unlikely. Although cord blood could not be examined for radioactivity in the present experiments, insignificant amounts of radioactivity have been found in cord blood when similar experiments were performed in women immediately before delivery of normal infants.

The production rate (milligrams per day) of E2 $\left(P R_{E 2}\right)$ is calculated from the expression

$$
\mathrm{PR}_{\mathrm{E} 2}=\frac{\mathrm{R}^{\mathrm{E}_{2} \mathrm{H}^{3}}}{\mathrm{sa}_{\mathrm{E} 2} \mathrm{H}^{3} \cdot \mathrm{t}},
$$

where $\mathrm{RE} 2 \mathrm{H}^{3}=$ the injected radioactivity (counts per minute) in the estradiol tracer; $\mathrm{sa}_{\mathrm{E} 2} \mathrm{H}^{\mathbf{3}}$ is the specific activity (counts per minute per milligram) of the isolated urinary E2 relative to the isotope, tritium, derived from the injected $\mathrm{E} 2 \mathrm{H}^{3}$ tracer; and $\mathrm{t}$ is the time of 
urine collection (days), which, in these experiments, was uniformly 5 days. Since the tracer is injected into the maternal vein, its metabolic fate will principally reflect maternal estradiol catabolism (see above). Therefore, as pointed out by Gurpide, Angers, Vande Wiele, and Lieberman, the production rate of estradiol calculated by the expression shown above probably represents the secretion rate of this hormone into the maternal compartment (21). This may not represent total placental estradiol production as pointed out in the excellent mathematical analyses of the problems of isotope dilution studies in situations analogous to pregnancy presented by Laumas, Tait, and Tait (22) and also by Gurpide, Mann, Vande Wiele, and Lieberman (23).

The production rate of $\mathrm{DS}\left(\mathrm{PR}_{\mathrm{Ds}}\right)$ is calculated from the expression

$$
\mathrm{PR}_{\mathrm{DS}}=\frac{\mathrm{RD}^{\mathrm{C}^{14} \mathrm{~S}}}{\mathrm{sa}_{\mathrm{DS}} \mathrm{C}^{14} \cdot \mathrm{t}}
$$

where $\mathrm{RD}^{\mathrm{C}^{14} \mathrm{~S}}$ is the amount of radioactivity (counts per minute) injected as $\mathrm{D}^{\mathrm{C}^{14}} \mathrm{~S}$, and $\mathrm{sans}^{\mathrm{C}^{14}}$ is the specific activity (counts per minute $\mathrm{C}^{14}$ per milligram) of urinary $\mathrm{D}(\mathrm{S}) .5 \quad$ In this instance the form of the urinary metabolite and the substance whose production rate is being measured, namely DS, are identical. Under this unique circumstance the theoretical objections to the validity of the measurements of some production rates (e.g., E2) in pregnancy do not obtain. The entry of DS into the maternal compartment by adrenal secretion, by transfer from the fetus, or by its peripheral formation from other secreted products will be measured as a part of the production rate of $\mathrm{DS}$ in the maternal compartment. All DS that enters the maternal compartment for the first time per unit time constitutes the maternal production rate of DS. This definition is consistent with that of Gurpide, Mann, and Lierberman for production rates in nonpregnant subjects (24).

TABLE I

Estradiol production in subject $M M-38^{*}$

\begin{tabular}{|c|c|c|c|c|}
\hline \multirow[b]{2}{*}{ Isotope } & \multicolumn{3}{|c|}{$\begin{array}{l}\text { Specific activities of } \\
\text { urinary metabolites }\end{array}$} & \multirow{2}{*}{$\begin{array}{l}\text { Production } \\
\text { rate } \\
\text { E2 }\end{array}$} \\
\hline & $\overline{\mathrm{E} 1}$ & E2 & E3 & \\
\hline & \multicolumn{3}{|c|}{$c m p / \mu g$} & $m g / d a y$ \\
\hline $\mathrm{H}^{3} \dagger$ & 440 & 436 & 324 & \\
\hline$C^{14} \ddagger$ & 0 & 0 & 0 & \\
\hline
\end{tabular}

${ }^{*} \mathrm{E} 1$ = urinary estrone; $\mathrm{E} 2$ = urinary estradiol, E3 = urinary estriol.

$\dagger$ Injected tracer dose of $\mathrm{E} 2 \mathrm{H}^{3}=4.7 \times 10^{6} \mathrm{cpm}$. Specific activities relative to tritium are corrected to the molecular weight of E2.

$\ddagger$ Injected tracer dose of $\mathrm{C}^{14}$-progesterone $=2 \times 10^{6}$ cpm.

${ }^{5}$ The specific activity of urinary $\mathrm{D}(\mathrm{S})$ is determined after solvolysis to yield $\mathrm{D}$ and is expressed as counts per minute per milligram $D$. Similarly, the production rates of DS are calculated from this specific activity and are expressed as milligrams per day equivalents of $D$.
The portion of estradiol production derived from the utilization of DS circulating in the maternal plasma $\left(\mathrm{PR}_{\mathrm{E} 2 / \mathrm{DS}}\right)$ is calculated from the expression

$$
\mathrm{PR}_{\mathrm{E} 2 / \mathrm{DS}}=\left(\mathrm{PR}_{\mathrm{E} 2}\right) \frac{\mathrm{sa}_{\mathrm{E} 2} \mathrm{C}^{14}}{\mathrm{sa}_{\mathrm{DS}}{ }^{\mathrm{C} 14}}
$$

where $\mathrm{sa}_{\mathrm{E2}} \mathrm{C}^{14}$ is the specific activity of urinary estradiol relative to $\mathrm{C}^{14}$ (derived from the injected $\mathrm{D}^{\mathrm{C}^{14}} \mathrm{~S}$ tracer), and $\mathrm{sa}_{1 \mathrm{~s}} \mathrm{C}^{14}$ is the specific activity of urinary DS. If estradiol production occurred only through the utilization of DS circulating in the maternal plasma, the specific activities of urinary DS and $\mathrm{E} 2$ relative to $\mathrm{C}^{\mathbf{1 4}}$ (corrected for differences in molecular weight) will be identical, and $\mathrm{PR}_{\mathrm{E} 2 / \mathrm{DS}}=\mathrm{PR}_{\mathrm{E} 2 \text {. }}$

\section{Experiment $I$}

\section{Results}

Estradiol production in subject $M M-38$. The specific activities of urinary E1, E2, and E3 after the administration of tritium-labeled estradiol and $\mathrm{C}^{14}$-progesterone to subject MM-38 are presented in Table I. There was no detectable $\mathrm{C}^{14}$ label in the isolated urinary estrogens indicating that the progesterone tracer was not converted to estrogen or was converted in such poor yield that it was not detected by these methods.

The specific activities of $\mathrm{E} 1$ and $\mathrm{E} 2$ relative to the tritium label (administered tracer: $\mathrm{E} 2^{\mathrm{H}^{3}}$ ) were similar. However, the specific activity of E3 was $25 \%$ lower than E1 or E2. This contrasts with the findings in women pregnant at term with a normal fetus wherein the specific activity of E3 is much lower than that of E1 or E2 after the administration of isotope-labeled E2 (21, 25 ). Based on the dilution of the injected tracer, $\mathrm{E} 2 \mathrm{H}^{3}$, according to the specific activity of urinary E2 isolated from the 5-day urine collection, the $\mathrm{PR}_{\mathrm{E} 2}$ was $2.1 \mathrm{mg}$ per day in this subject.

\section{Experiment II}

Utilization of circulating dehydroisoandrosterone sulfate for estrogen synthesis in subject $M M-38$. The specific activities of urinary $\mathrm{E} 1$, $\mathrm{E} 2$, and $\mathrm{E} 3$ relative to tritium and to $\mathrm{C}^{14}$, and of DS relative to $\mathrm{C}^{14}$ after the intravenous administration of a tracer dose of $\mathrm{E} 2^{\mathrm{H}^{3}}$ and $\mathrm{D}^{\mathrm{C}^{14}} \mathrm{~S}$ to MM-38 are shown in Table II. As in the preceding study, the specific activity of estriol relative to the label derived from the tracer $\mathrm{E} 2 \mathrm{H}^{3}$ is less than those of urinary E1 or E2, which are similar. However, the specific activities of urinary $\mathrm{E} 1, \mathrm{E} 2$, and $\mathrm{E} 3$ relative to $\mathrm{C}^{14}$, which was derived 
TABLE II

Origin of estrogen in subject $M M-38$; fraction of $D^{\mathrm{C}^{14}} S$ converted to $E 2=30 \% *$

\begin{tabular}{|c|c|c|c|c|c|c|c|}
\hline \multirow[b]{2}{*}{ Isotope } & \multicolumn{4}{|c|}{$\begin{array}{l}\text { Specific activities of } \\
\text { urinary metabolites }\end{array}$} & \multicolumn{3}{|c|}{ Production rate } \\
\hline & $\mathrm{E} 1$ & $\mathrm{E} 2$ & E3 & $\mathrm{D}(\mathrm{S})$ & $\mathrm{DS} \dagger$ & E2 & E2DS \\
\hline & \multicolumn{4}{|c|}{$c p m / \mu g$} & \multicolumn{3}{|c|}{$m g / d a y$} \\
\hline $\mathrm{H}^{3} \ddagger$ & 339 & 353 & 117 & & \multirow{2}{*}{5.8} & \multirow{2}{*}{1.7} & \multirow{2}{*}{1.7} \\
\hline $\mathrm{C}^{148}$ & 185 & 170 & 161 & 172 & & & \\
\hline
\end{tabular}

$* \mathrm{DS}=$ dehydroisoandrosterone sulfate.

$\dagger$ Production rate of DS is expressed as milligrams per day equivalents of $D$.

¥ Specific activities relative to tritium are corrected to a common tracer dose of $3 \times 10^{6} \mathrm{cpm} \mathrm{E2 \textrm {H } ^ { 3 }}$ and to the molecular weight of E2. $\$$ Specific activities relative to $\mathrm{C}^{14}$ are corrected to a common trace dose of $5 \times 10^{6} \mathrm{cpm} \mathrm{Dc}^{14} \mathrm{~S}$ and to the molecular weight of $\mathrm{D}$.

from the tracer $\mathrm{D}^{\mathrm{C}}{ }^{14} \mathrm{~S}$, are similar and, indeed, are the same as that of urinary DS. The identity of the specific activities relative to $\mathrm{C}^{14}$ of the urinary estrogens with the specific activity of urinary DS indicates that estrogen production in this subject was derived exclusively from the utilization of dehydroisoandrosterone sulfate circulating in the maternal plasma. From the specific activity of urinary DS, the production rate of DS was calculated to be $5.8 \mathrm{mg}$ per day. Similarly, from the specific activity of urinary E2 relative to tritium, the production rate of $\mathrm{E} 2$ was calculated to be 1.7 $\mathrm{mg}$ per day (compared with a value of $2.1 \mathrm{mg}$ per day obtained in the previous experiment in the same subject).

Since the specific activity of urinary E3 relative to tritium, derived from the $\mathrm{E} 2 \mathrm{H}^{\mathrm{H}}$ tracer, was less than the specific activity of urinary E1 or E2 relative to tritium, it is apparent that E3 was not exclusively derived from maternal E2 catabolism. However, since the urinary E1, E2, and E3 specific activities relative to $\mathrm{C}^{14}$, derived from the $\mathrm{D}^{\mathrm{C}^{14}} \mathrm{~S}$ tracer, were the same, and, indeed, the same as that of urinary DS, it is concluded that a portion of the $\mathrm{E} 3$ produced in this subject was derived from DS via a pathway other than maternal E1 catabolism. Similar findings were previously reported $(5,26)$.

From the relationship of the $\mathrm{H}^{3} / \mathrm{C}^{14}$ ratio of isolated urinary $\mathrm{E} 2$ to the $\mathrm{H}^{3} / \mathrm{C}^{14}$ ratio of the injected tracers; the fraction of $\mathrm{D}^{\mathrm{C}}{ }^{14} \mathrm{~S}$ converted to E2 was calculated to be $30 \%$.

\section{Experiment III}

Utilization of dehydroisoandrosterone sulfate for estrogen production in subject $A B-35$. The re- sults of experiment III are shown in Table III. The results of this study are very similar to those of experiment II. The specific activity of urinary E3 relative to the isotope of the injected estradiol tracer, $\mathrm{E} 2 \mathrm{H}^{3}$, is $46 \%$ less than the specific activity of urinary E1 or E2 relative to tritium. However, the specific activities of urinary E1, E2, and E3 relative to the isotope derived from the $\mathrm{D}^{\mathrm{C}} \mathrm{S}$ tracer are similar and, indeed, again these are very nearly the same as that of urinary DS. In this case the production rate of E2 was $1.2 \mathrm{mg}$ per day, the production rate of DS was $3.6 \mathrm{mg}$ per day, and the amount of E2 derived from the utilization of DS circulating in the maternal plasma $\left(\mathrm{PR}_{\mathrm{E} 2 / \mathrm{DS}}\right)$ was $1.0 \mathrm{mg}$ per day. This represents $83 \%$ of the total $\mathrm{E} 2$ production entering the maternal compartment. In this subject, as in MM$38,30 \%$ of the injected tracer $\mathrm{D}^{\mathrm{C}}{ }^{14} \mathrm{~S}$ was converted to E2. Again, as in experiment II, the operation of an E2 independent pathway of E3 production from $\mathrm{DS}$ is evident.

\section{Experiment IV}

The specific activities of urinary DS, E1, E2, and $\mathrm{E} 3$ after the injection of $\mathrm{E} 2 \mathrm{H}^{3}$ and $\mathrm{D}^{\mathrm{C}}{ }^{14} \mathrm{~S}$ to subject LB-33 before and after dexamethasone treatment are shown in Table IV.

a) Utilization of dehydroisoandrosterone sulfate for estrogen production in subject LB-33 (before dexamethasone treatment). Before treatment with dexamethasone, the specific activities of urinary $\mathrm{E} 1, \mathrm{E} 2$, and $\mathrm{E} 3$ relative to tritium are similar. The specific activities of urinary E1, E2, and E3 relative to the $\mathrm{C}^{14}$ label are also similar, E3 being slightly higher. These, in turn, are 48,48 , and $54 \%$ that of the specific activity of urinary

TABLE III

Origin of estrogen in subject $A B-35$; fraction of $D^{\mathrm{C}^{14}} S$ converted to $E 2=30 \%$

\begin{tabular}{|c|c|c|c|c|c|c|c|}
\hline \multirow[b]{2}{*}{ Isotope } & \multicolumn{4}{|c|}{$\begin{array}{l}\text { Specific activities of } \\
\text { urinary metabolites }\end{array}$} & \multicolumn{3}{|c|}{ Production rate } \\
\hline & E1 & E2 & E3 & $\mathrm{D}(\mathrm{S})$ & DS* & E2 & E2Ds \\
\hline & \multicolumn{4}{|c|}{$c p m / \mu g$} & \multicolumn{3}{|c|}{$m g / d a y$} \\
\hline $\mathrm{H}^{3}+$ & 510 & 530 & 286 & & \multirow{2}{*}{3.6} & \multirow{2}{*}{1.2} & \multirow{2}{*}{1.0} \\
\hline$C^{14} \ddagger$ & 242 & 243 & 227 & 279 & & & \\
\hline
\end{tabular}

* Production rate of DS is expressed as milligrams per day equivalents of $\mathrm{D}$.

† Specific activities relative to tritium are corrected to a common tracer dose of $3 \times 10^{6} \mathrm{cpm} \mathrm{E2} \mathrm{H}^{3}$ and to the molecular wieght of E2. ¥ Specific activities relative to $\mathrm{C}^{14}$ are corrected to a common tracer dose of $5 \times 10^{6} \mathrm{cpm} \mathrm{Dc^{14 } S}$ and to the molecular weight of $D$. 
TABLE IV

Origin of estrogen in subject $L B-33$

\begin{tabular}{|c|c|c|c|c|c|c|c|c|c|c|c|c|c|c|c|}
\hline & \multicolumn{7}{|c|}{ Before dexamethasone } & & \multicolumn{7}{|c|}{ After dexamethasone } \\
\hline & \multicolumn{7}{|c|}{ Fraction of $\mathrm{Dc}^{14} \mathrm{~S}$ converted to $\mathrm{E} 2=34 \%$} & & \multicolumn{7}{|c|}{ Fraction of $\mathrm{Dc}^{14} \mathrm{~S}$ converted to $\mathrm{E} 2=35 \%$} \\
\hline & \multicolumn{4}{|c|}{$\begin{array}{l}\text { Specific activities of } \\
\text { urinary metabolites }\end{array}$} & \multicolumn{3}{|c|}{ Production rate } & \multirow[b]{2}{*}{ Isotope } & \multicolumn{4}{|c|}{$\begin{array}{l}\text { Specific activities of } \\
\text { urinary metabolites }\end{array}$} & \multicolumn{3}{|c|}{ Production rate } \\
\hline \multirow[t]{2}{*}{ Isotope } & E1 & E2 & E3 & $\mathrm{D}(\mathrm{S})$ & DS* & E2 & $\overline{E 2 D S}$ & & $\overline{\mathrm{E} 1}$ & E2 & E3 & $\overline{D(S)}$ & DS* & E2 & E2Ds \\
\hline & & \multicolumn{2}{|c|}{$c p m / \mu g$} & & \multicolumn{3}{|c|}{$m g / d a y$} & & \multicolumn{3}{|c|}{$c p m / \mu g$} & & \multicolumn{3}{|c|}{$m g / d a y$} \\
\hline $\mathrm{H}^{3}+$ & 80 & 80 & 74 & & \multirow{2}{*}{10.8} & \multirow{2}{*}{7.5} & \multirow{2}{*}{3.6} & $\mathrm{H}^{3}+$ & 222 & 210 & 158 & & \multirow{2}{*}{2.8} & \multirow{2}{*}{2.7} & \multirow{2}{*}{1.0} \\
\hline $\mathrm{C}^{14} \ddagger$ & 45 & 46 & 50 & 93 & & & & $\mathrm{C}^{14} \ddagger$ & 133 & 120 & 96 & 357 & & & \\
\hline
\end{tabular}

* Production rate of DS is expressed as milligrams per day equivalents of D.

† Specific activities relative to tritium are corrected to a common tracer dose of $3 \times 10^{6} \mathrm{cpm} \mathrm{E2} 3$ and to the molecular weight of E2.

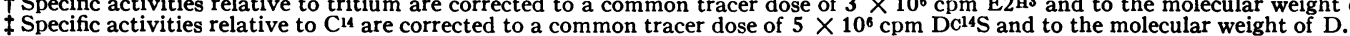

DS. Therefore in this subject, one-half $(3.6 \mathrm{mg}$ per day) of the total estrogen produced $(7.5 \mathrm{mg}$ per day) was derived from the utilization of DS circulating in the maternal plasma. The $P_{D S}$ was $10.8 \mathrm{mg}$ per day. The fraction of $\mathrm{D}^{\mathrm{C}^{14}} \mathrm{~S}$ converted to $\mathrm{E} 2$ was $34 \%$.

In subject LB-33 the specific activities of urinary $\mathrm{E} 1$ and $\mathrm{E} 3$ relative to both tritium and $\mathrm{C}^{\mathbf{1 4}}$ are not significantly different, and therefore appreciable estriol was not formed from DS independent of the maternal catabolism of E2 in this subject.

b) Effect of adrenal suppression on dehydroisoandrosterone sulfate and estradiol production in subject LB-33. After dexamethasone treatment the specific activities of urinary E1, E2, and E3 relative to tritium and to $\mathrm{C}^{14}$ were much higher than in the preceding experiment in this subject before treatment. (The amount of radioactivity in the injected tracers and the length of urine collection were identical in each experiment.) The production rate of $\mathrm{E} 2$ decreased from $7.5 \mathrm{mg}$ per day before treatment to $2.7 \mathrm{mg}$ per day during adrenal suppression, whereas estradiol produced from the utilization of maternal circulating DS decreased from $3.6 \mathrm{mg}$ per day to $1.0 \mathrm{mg}$ per day. Of fundamental importance is the fact that the fraction of the tracer $\mathrm{D}^{\mathrm{C}^{14}} \mathrm{~S}$ converted to $\mathrm{E} 2$ in this subject was the same before $(34 \%)$ dexamethasone treatment despite a decrease in DS production from 10.8 to $2.8 \mathrm{mg}$ per day. Therefore, the administration of dexamethasone did not alter the efficiency of utilization of DS for estrogen production but rather decreased the amount of precursor DS available for this process. It should be pointed out, however, that the decrease in estrogen production after dexamethasone treatment ( 7.5 to $2.7=4.8-\mathrm{mg}$ decrease) was greater than can be accounted for by the decrease in estradiol production derived from maternal DS (3.6 to $1.0=2.6-\mathrm{mg}$ decrease).

\section{Experiment $V$}

The results of the study in subject JV-35 before and after ACTH administration are presented in Table $\mathrm{V}$.

a) Utilization of dehydroisoandrosterone sulfate for estrogen production in subject $J V-35$

TABLE V

Origin of estrogen in subject $J V-35$

\begin{tabular}{|c|c|c|c|c|c|c|c|c|c|c|c|c|c|c|c|}
\hline & \multicolumn{7}{|c|}{ Before ACTH } & & \multicolumn{7}{|c|}{ After ACTH } \\
\hline & \multicolumn{7}{|c|}{ Fraction of $\mathrm{DC}^{14} \mathrm{~S}$ converted to $\mathrm{E} 2=40 \%$} & & \multicolumn{7}{|c|}{ Fraction of $\mathrm{Dc}^{14} \mathrm{~S}$ converted to $\mathrm{E} 2=41 \%$} \\
\hline & \multicolumn{4}{|c|}{$\begin{array}{l}\text { Specific activities of } \\
\text { urinary metabolites }\end{array}$} & \multicolumn{3}{|c|}{ Production rate } & \multirow[b]{2}{*}{ Isotope } & \multicolumn{4}{|c|}{$\begin{array}{l}\text { Specific activities of } \\
\text { urinary metabolites }\end{array}$} & \multicolumn{3}{|c|}{ Production rate } \\
\hline \multirow[t]{2}{*}{ Isotope } & E1 & E2 & E3 & $\mathrm{D}(\mathrm{S})$ & DS* & E2 & E2DS & & E1 & E2 & E3 & $\mathrm{D}(\mathrm{S})$ & DS* & E2 & E2DS \\
\hline & & \multicolumn{2}{|c|}{$c p m / \mu g$} & & \multicolumn{3}{|c|}{$m g / d a y$} & & \multicolumn{4}{|c|}{$c p m / \mu g$} & \multicolumn{3}{|c|}{$m g / d a y$} \\
\hline $\mathrm{H}^{3} \dagger$ & 348 & 334 & 172 & & \multirow{2}{*}{4.7} & \multirow{2}{*}{1.8} & \multirow{2}{*}{1.8} & $\mathrm{H}^{3}+$ & 75 & 76 & 55 & & \multirow{2}{*}{19.3} & \multirow{2}{*}{8.0} & \multirow{2}{*}{7.6} \\
\hline$C^{14} \ddagger$ & 219 & 210 & 183 & 210 & & & & $\mathrm{C}^{14}$ & 49 & 48 & 52 & 52 & & & \\
\hline
\end{tabular}

* Production rate of DS is expressed as milligrams per day equivalents of D.

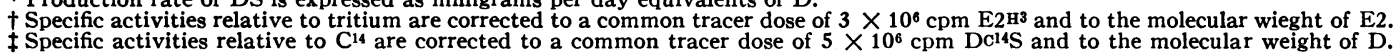


(before ACTH treatment). Before ACTH treatment the $\mathrm{PR}_{\mathrm{E} 2}$ in this subject of $1.8 \mathrm{mg}$ per day was very similar to that found in subjects MM-38 and AB-35. These amounts were much lower than those found in women at comparable stages of pregnancy with a normal fetus. Again, as in experiments II and III, the specific activity of urinary $\mathrm{E} 3$ was only $50 \%$ that of urinary $\mathrm{E} 1$ or E2 relative to tritium, but nearly identical relative to $\mathrm{C}^{14}$. Again the specific activities of the urinary estrogens and DS relative to $\mathrm{C}^{14}$ were very similar. Therefore the $1.8 \mathrm{mg}$ per day of E2 produced each day was derived exclusively from the utilization of DS circulating in the maternal plasma. The $P R_{D S}$ in this case was $4.7 \mathrm{mg}$ per day.

b) Effect of adrenal stimulation on dehydroisoandrosterone sulfate and estradiol production in subject $J V-35$. From the marked decrease in the specific activities of the urinary metabolites after ACTH treatment compared with these values before ACTH it is apparent that an increase in the production rate of both $\mathrm{E} 2$ and $\mathrm{DS}$ occurred. The $\mathrm{PR}_{\mathrm{E} 2}$ increased from $1.8 \mathrm{mg}$ per day before ACTH treatment to $8.0 \mathrm{mg}$ per day during the administration of $A C T H$. The $\mathrm{PR}_{\mathrm{Ds}}$ increased from $4.7 \mathrm{mg}$ per day to $19.3 \mathrm{mg}$ per day. Despite the fourfold increase in $\mathrm{PR}_{\mathrm{DS}}$, the fraction of the injected tracer $D^{{ }^{14}} \mathrm{~S}$ converted to $\mathrm{E} 2$ was $41 \%$, essentially the same as that observed before treatment with ACTH, 40\%. Therefore augmented $\mathrm{PR}_{\mathrm{E} 2}$ is accounted for by an increase in available precursor, $\mathrm{DS}$, as evidenced by a $\mathrm{PR}_{\mathrm{E} 2 / \mathrm{Ds}}$ of 7.6 $\mathrm{mg}$ per day compared with a $\mathrm{PR}_{\mathrm{E} 2}$ of $8.0 \mathrm{mg}$ per day.

\section{Discussion}

The fraction of injected isotope-labeled DS tracer converted to estradiol in vivo in all four subjects studied (30 to $41 \%$ ) is similar to that which has been observed in women pregnant with a normal fetus near term (7). It is of particular interest to note that conversion of the isotopelabeled DS to E2 was the same in subject LB-33 before and after dexamethasone administration despite almost a fourfold decrease in DS production. Furthermore, the same magnitude of conversion of $\mathrm{D}^{\mathrm{C}}{ }^{14} \mathrm{~S}$ to $\mathrm{E} 2$ was observed before and after ACTH administration to subject AB-35 despite a fourfold increase in DS production.
(The conversion of DS to E2 measured by these studies is the fraction of the injected tracer transformed to the hormone E2 in vivo and does not represent the fraction converted to a urinary product.) Assuming that the extent of conversion of the injected tracer $D^{\mathrm{C}^{14} \mathrm{~S}} \mathrm{~S}$ to $\mathrm{E} 2$ reflects the over-all rate of utilization of both tracer and endogenous DS, these data suggest that the entry of precursor into the placenta and/or the tissue concentration of the many enzymes and cofactors involved in this conversion were not rate limiting in the range of these studies.

The levels of production of estradiol in three of the four subjects of this study of $1.2,1.7$, and $1.8 \mathrm{mg}$ per day are approximately one-tenth those observed at comparable stages of gestation in women pregnant with a normal fetus. The adrenal cortices of the fetuses of these three subjects were characterized by marked hypoplasia of the fetal zone. In these three subjects 83 to $100 \%$ of estradiol production was derived from the utilization of dehydroisoandrosterone sulfate circulating in the maternal plasma.

The $\mathrm{PR}_{\mathrm{E} 2}$ of $7.5 \mathrm{mg}$ per day in the fourth subject, LB-33, is only moderately reduced when compared with women pregnant with a normal fetus at 33 weeks gestation. Frandsen and Stakeman also observed one instance of relatively higher estrogen excretion by a woman pregnant with an anencephalic fetus and noted that in this case there was greater fetal zone development than in the other cases. The correlation between the extent of fetal zone development and the level of maternal urinary estrogen excretion provided additional support for their hypothesis that placental estrogen formation resulted from the utilization of a steroidal precursor arising in the fetal adrenal glands. Unfortunately, such a relationship could be neither confirmed nor denied in the present case (LB-33) since post-mortem examination of the anencephalic monster delivered of this subject was not possible. However, one explanation of the relatively higher production of E2 in this case, only one-half of which was derived from maternal DS, is that the fetal adrenals were also contributing quantitatively important amounts of placental estrogen precursor.

Bolté and co-workers have reported that isotope-labeled DS perfused through the in situ placenta via the umbilical artery is also converted 
to estrone and/or estradiol (12). Their findings and those of the present report support the concept that the normal fetal adrenal contributes a substance in significant quantities which the placenta utilizes for estrogen synthesis. Furthermore, it is highly likely that the predominant blood-borne precursor is dehydroisoandrosterone sulfate. Gardner and Walton have shown that the level of total neutral 17 -ketosteroids is higher in fetal than in maternal blood at the time of delivery (27). More specifically, Migeon, Keller, and Holmstrom (14) as well as Colás, Heinrichs, and Tatum (15) have reported that the cord plasma levels of DS are higher in the normal newborn than in the mother, but there are negligible to absent levels of DS in the cord blood of anencephalic monsters (16). Therefore it is probable that DS, arising from both maternal and fetal sources, serves as an important precursor of estrogen during pregnancy.

The results of the present study also demonstrate that alterations in the level of production of an externally supplied precursor, DS, can profoundly affect placental estrogen production. This is evident from the marked reduction of E2 production, 7.5 to $2.8 \mathrm{mg}$ per day, which was observed in LB-33 after the administration of dexamethasone. That the decrease in estrogen production was, in part, consequent to the lowering of the amount of maternal DS available from 10.8 to $2.8 \mathrm{mg}$ per day is illustrated by the reduction of the amount of E2 derived from maternal DS from 3.6 to $1.0 \mathrm{mg}$ per day. Conversely, an increase in the amount of available DS from 4.8 to $19.3 \mathrm{mg}$ per day after ACTH administration to JV-35 was associated with an increase in E2 production from 1.8 to $8.0 \mathrm{mg}$ per day.

As noted above, the $4.7-\mathrm{mg}$ decrease in total E2 production after dexamethasone administration to LB-33 was greater than can be accounted for by the 2.6-mg decrease in the amount of E2 that was derived from maternal DS. Although this result may be accounted for by suppression of the fetal adrenal, in this case there is no direct evidence to support this conclusion.

It is well known that there is a disproportionate increase in urinary estriol excreted in the urine of pregnant women (28) that cannot be accounted for by the maternal catabolism of E2 $(21,25$,
28). It has been postulated that the fraction of estriol in pregnancy urine not derived from maternal estrone catabolism may represent placental secretion of estriol, perhaps via its synthesis from a 16-hydroxy neutral precursor (29), or, as postulated by Bolté and associates, estriol may arise by $16 \alpha$-hydroxylation in the fetus of placental estrone, followed by reduction to estriol in the placenta (10). In the present study more isotope derived from the injected DS tracer appeared in urinary $\mathrm{E} 3$ than could be accounted for by the maternal catabolism of isotope-labeled E2 derived from the same source. This was apparent from the fact that with respect to the isotope derived from the injected $D^{\mathrm{c}}{ }^{14} \mathrm{~S}$, the specific activity of $\mathrm{E} 3$ was similar to those of E1 and E2 in all cases, whereas the specific activity of $\mathrm{E} 3$ relative to the isotope derived from the injected $\mathrm{E} 2 \mathrm{H}^{3}$ was onethird that of E1 and E2 in MM-38 and AB-35, one-half that of E1 and E2 in JV-35, and similar to $\mathrm{El}$ in only one case, LB-33. This finding may be explained by a preferential entry of isotope from the $\mathrm{D}^{114} \mathrm{~S}$ tracer as either a $\mathrm{C}_{19}$ or $\mathrm{C}_{18}$ compound into the fetal compartment where 16hydroxylation occurred. Alternatively, 16-hydroxylation of DS may have been accomplished via maternal metabolism, e.g., in the maternal liver, such that a 16-hydroxylated neutral steroid, e.g., $16 \alpha \mathrm{OH}$-dehydroisoandrosterone sulfate (16$\mathrm{OH}-\mathrm{DS}$ ), was made available to the placenta for conversion to estriol. A preliminary report of data obtained in this laboratory that supports, but does not quantitate, this latter mechanism has been presented (26).

It is likely that the fetal participation in estriol precursor production is paramount in pregnancies near term with a normal fetus. The finding of large amounts of $16 \alpha \mathrm{OH}$-dehydroisoandrosterone in umbilical blood $(15,30)$ as well as in the urine of the newborn $(31,32)$ together with the in vivo demonstration of estriol formation from isotopelabeled 16-OH-D during pregnancy (26) strongly suggests that placental estriol may arise largely from 16-OH-DS originating in the fetal compartment. The results of the present study provide additional evidence for this mechanism. Although the specific activity of estriol relative to the isotope derived from the injected E2 tracer was 33 to $100 \%$ that of $\mathrm{E} 1$ and $\mathrm{E} 2$ in the present study, in pregnancy with a normal fetus during 
the last 8 weeks of gestation it may be only $10 \%$ or less that of the other metabolites. Thus it is likely that during normal pregnancy the maternal and fetal adrenal directly contributes not only to placental E2 production but to placental estriol synthesis as well. The delineation of the ultimate source of fetal 16-OH-DS must await further experiments.

It may be concluded that the placenta relies heavily if not exclusively upon externally supplied neutral precursors for estrogen synthesis, and further, that variation in the level of production of these precursors effects significant alterations in placental estrogen production. It is apparent, therefore, that the over-all level of production and urinary excretion of estrogen during pregnancy is not singularly a reflection of placental function but rather is dependent upon a number of factors, perhaps the most important of which is the supply of precursor(s) delivered to the placenta. Thus the interpretation of atypical urinary estrogen levels observed in various abnormalities of pregnancy in terms of a specific physiological or biochemical defect is presently not possible.

\section{Summary}

The genesis of estrogen in four patients pregnant with an anencephalic fetus has been studied. The results indicate that the bulk (50 to $100 \%$ ) of the estrogen produced by these subjects was derived from the placental utilization of dehydroisoandrosterone sulfate circulating in the maternal plasma. In addition, evidence is presented for the synthesis of estriol from dehydroisoandrosterone sulfate through a pathway that does not involve estrone or estradiol.

The results of this study further indicate that induced changes in the level of production of precursor, dehydroisoandrosterone sulfate, effected similar changes in the level of production of estrogen.

On the basis of these results it is suggested that the placenta relies heavily, perhaps exclusively, upon externally supplied $\mathrm{C}_{19}$ precursors for estrogen synthesis, and that these precursors may arise in either the maternal or fetal compartment.

\section{Acknowledgments}

We gratefully acknowledge the cooperation of the resident staff in Obstetrics, Parkland Memorial Hospital, Dallas, Texas, who referred these patients for this study. In addition, we thank Miss Elsie Ewen and Mr. Frank Hereford for their skillful technical assistance.

\section{References}

1. Frandsen, V. A., and G. Stakeman. The site of production of oestrogenic hormones in human pregnancy. Hormone excretion in pregnancy with anencephalic foetus. Acta endocr. (Kbh.) 1961, 38, 383.

2. Frandsen, V. A., and G. Stakeman. The site of production of oestrogenic hormones in human pregnancy. II. Experimental investigations on the role of the foetal adrenal. Acta endocr. (Kbh.) 1963, 43, 184.

3. Levitz, M., S. Emerman, and J. Dancis. Sterol synthesis in perfused human placenta (abstract). Excerpta med. (Amst.) 1962, 51, 266.

4. Ryan, K. J. Aromatization of steroids. J. biol. Chem. 1959, 234, 268.

5. Siiteri, P. K., and P. C. MacDonald. The utilization of circulating dehydroisoandrosterone sulfate for estrogen synthesis during human pregnancy. Steroids 1963, 2, 713.

6. MacDonald, P. C., and P. K. Siiteri. The conversion of isotope-labeled dehydroisoandrosterone and dehydroisoandrosterone sulfate to estrogen in normal and abnormal pregnancy in Workshop on Estrogens, A. Paulsen, Ed. Seattle, Univ. of Wash. Press, in press.

7. MacDonald, P. C., and P. K. Siiteri. Utilization of circulating dehydroisoandrosterone sulfate for estrogen synthesis during human pregnancy (abstract). Clin. Res. 1964, 12, 67.

8. Baulieu, E. E., and F. Dray. Conversion of $\mathrm{H}^{3}$-dehydroisoandrosterone ( $3 \beta$-hydroxy- $\Delta^{5}$-androsten-17one) sulfate to $\mathrm{H}^{3}$-estrogens in normal pregnant women. J. clin. Endocr. 1963, 23, 1298.

9. Bolté, E., S. Mancuso, G. Eriksson, M. Wiquist, and E. Diczfalusy. Studies on the aromatisation of neutral steroids in pregnant women. 2. Aromatisation of dehydroisoandrosterone and of its sulphate administered simultaneously into a uterine artery. Acta endocr. (Kbh.) 1964, 45, 560.

10. Bolté, E., S. Mancuso, G. Eriksson, N. Wiquist, and E. Diczfalusy. Studies on the aromatisation of neutral steroids in pregnant women. 3. Over-all aromatisation of dehydroisoandrosterone sulphate circulating in the foetal and maternal compartments. Acta endocr. (Kbh.) 1964, 45, 576.

11. Warren, J. C., and C. E. Timberlake. Biosynthesis of estrogens in pregnancy: precursor role of plasma dehydroisoandrosterone. Obstet. and Gynec. 1964, 23, 689 . 
12. Bolté, E., S. Mancuso, G. Eriksson, N. Wiquist, and E. Diczfalusy. Studies on the aromatisation of neutral steroids in pregnant women. 1. Aromatisation of C-19 steroids by placentas perfused in situ. Acta endocr. (Kbh.) 1964, 45, 535.

13. Vande Wiele, R. L., P. C. MacDonald, E. Gurpide, and S. Lieberman. Studies on the secretion and interconversion of the androgens. Recent Progr. Hormone Res. 1963, 19, 275.

14. Migeon, C. J., A. R. Keller, and E. G. Holmstrom. Dehydroisoandrosterone, androsterone and 17-hydroxycorticosteroid levels in maternal and cord plasma in cases of vaginal delivery. Bull. Johns Hopk. Hosp. 1955, 97, 415.

15. Colás, A., W. L. Heinrichs, and H. J. Tatum. Pettenkofer chromogens in the maternal and fetal circulations : detection of $3 \beta, 16 \alpha$-dihydroxyandrost-5en-17-one in umbilical cord blood. Steroids 1964, 3, 417.

16. Nichols, J., O. L. Lescure, and C. J. Migeon. Levels of 17-hydroxycorticosteroids and 17-ketosteroids in maternal and cord plasma in term anencephaly. J. clin. Endocr. 1958, 18, 444.

17. Siiteri, P. K. The isolation of urinary estrogens and determination of their specific activities following the administration of radioactive precursors to humans. Steroids 1963, 2, 687.

18. Burstein, S., and S. Lieberman. Hydrolysis of ketosteroid hydrogen sulfates by solvolysis procedures. J. biol. Chem. 1958, 233, 331.

19. Siiteri, P. K., R. L. Vande Wiele, and S. Lieberman. Occurrence of dehydroisoandrosterone glucuronoside in normal human urine. J. clin. Endocr. 1963, 23, 588.

20. Vande Wiele, R. L., P. C. MacDonald, E. Bolté, and S. Lieberman. Precursors of the urinary 11desoxy-17-ketosteroids : estimation of the secretory rate of dehydroisoandrosterone. J. clin. Endocr. 1962, 22, 1207.

21. Gurpide, E., M. Angers, R. Vande Wiele, and S. Lieberman. Determination of secretory rates of estrogens in pregnant and nonpregnant women from the specific activities of urinary metabolites. J. clin. Endocr. 1962, 22, 935.
22. Laumas, K. R., J. F. Tait, and S. A. S. Tait. The validity of the calculation of secretion rates from the specific activity of a urinary metabolite. Acta endocr. (Kbh.) 1961, 36, 265.

23. Gurpide, E., J. Mann, R. L. Vande Wiele, and S. Lieberman. A discussion of the isotope dilution method for estimating secretory rates from urinary metabolites. Acta endocr. (Kbh.) 1962, 39, 213.

24. Gurpide, E., J. Mann, and S. Lieberman. Analysis of open systems of multiple pools by administration of tracers at a constant rate or as a single dose as illustrated by problems involving steroid hormones. J. clin. Endocr. 1963, 23, 1155.

25. Fishman, J., J. B. Brown, L. Hellman, B. Zumoff, and T. F. Gallagher. Estrogen metabolism in normal and pregnant women. J. biol. Chem. 1961, 237, 1489.

26. Siiteri, P. K., and P. C. MacDonald. The biogenesis of urinary estriol during human pregancy (abstract). Clin. Res. 1964, 12, 44.

27. Gardner, L. I., and R. L. Walton. Plasma 17-ketosteroids of the human fetus : demonstration of concentration gradient between cord and maternal circulations. Helv. paediat. Acta 1954, 9, fasc. 4, 311.

28. Pearlman, W. H., M. R. J. Pearlman, and A. E. Rakoff. Estrogen metabolism in human pregnancy; a study with the aid of deuterium. J. biol. Chem. 1954, 209, 803.

29. Ryan, K. J. Metabolism of C-16-oxygenated steroids by human placenta: the formation of estriol. J. biol. Chem. 1959, 234, 2006.

30. Magendantz, H. G., and K. J. Ryan. Isolation of a new estriol precursor. Fed. Proc. 1964, 23, 275.

31. Bongiovanni, A. M. The adrenogenital syndrome with deficiency of $3 \beta$-hydroxysteroid dehydrogenase. J. clin. Invest. 1962, 41, 2086.

32. Reynolds, J. W. The isolation of 16-keto-androstenediol ( $3 \beta, 17 \beta$-dihydroxyandrost-5-en-16-one) from the urine of a newborn infant. Steroids 1964, 3, 77. 